\title{
Rounded Rectangle
}

National Cancer Institute

\section{Source}

National Cancer Institute. Rounded Rectangle. NCI Thesaurus. Code C85855.

A shape similar to a rectangle but with corners that resemble an arc of a circle. 